\title{
Science Academies' Refresher Course on Multiomic Applications in Medicinal Plant Research
}

\author{
at \\ TransDisciplinary University, Bengaluru \\ 19 February to 03 March, 2018
}

\author{
Sponsored by \\ Indian Academy of Sciences, Bengaluru \\ Indian National Science Academy, New Delhi \\ The National Academy of Sciences, India, Allahabad
}

The course is aimed to benefit faculty involved in teaching life science undergraduate and postgraduate students. The objective of this course is to provide insight into the application of -omic methodologies and also to get familiar with laboratory techniques. This course is sponsored by Indian Academy of Sciences, Bengalaru, Indian National Science Academy, New Delhi and The National Academy of Sciences, India, Allahabad. The participants of the refresher course will have hands-on experience with the advanced laboratory facilities available in the University. Course includes lectures, discussions, laboratory experiments, problem solving sessions, field visit and walk the talk.

Refresher course is focused on the following broad subject areas; Introductions to Indian bioresources of medicinal plants, sustainable use of bio resources of India; Medicinal plants: traditional and pharmacological use; Recent advances in genomics and functional genomics, epigenomics and epigenetics, transcriptomics, proteomics, and metabolomics and data analysis.

Applications are invited from teachers with experience in teaching undergraduate and postgraduate courses in Life Sciences, Agriculture and Technology. Applications from highly motivated Research Scholars will also be considered. The maximum number of seats will be 35 . Teachers who wish to participate in the refresher course may apply through proper channel with the following details: name, date of birth, gender, e-mail, official and residential addresses, telephone numbers, academic qualifications, courses taught, affiliation, positions held and tenure. It is also essential to submit a brief statement (between 250 and 500 words) as to why they think the Course will help to improve their classroom teaching of Life Sciences. There will be NO applications fee/registration fee.

Applications should be submitted ONLINE by clicking the following link:

http://web-japps.ias.ac.in: 8080/Refreshcourse/MAMZ.jsp

A print copy of the application must also be sent by speed post forwarded by the head of the institution. It should reach Course Coordinator, Dr. Mohana Kumara P Assistant Professor, TransDisciplinary University, School of Integrative Health Sciences, 74/2 Jarakabande Kaval, Post Attur Yelahanka, Bengaluru, Karnataka, 560064, Email: mohan.kumar@tdu. edu.in on or before 9 Jan 2018. Outstation candidates will be provided local hospitality and round trip bus/train (three-tier AC) fare by the shortest route.

Course Director: Prof. R Uma Shaanker, Department of Crop Physiology and School of Ecology and Conservation, University of Agricultural Sciences, GKVK, Bengaluru.

Course Coordinator: Dr. Mohana Kumara P Assistant Professor, TransDisciplinary University, Bengaluru

Last date for receipt of applications: 9 January 2018

Selected participants will be informed on 20 January 2018 . 